\begin{tabular}{|c|c|}
\hline & $\begin{array}{l}\text { International Journal of Trend in Scientific } \\
\text { Research and Development (IJTSRD) }\end{array}$ \\
\hline 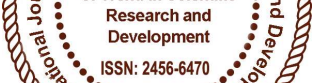 & International Open Access Journal \\
\hline 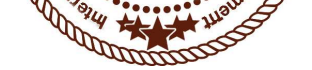 & ISSN No: 2456 - 6470 | www.ijtsrd.com | Volume - 2 | Issue - 2 \\
\hline
\end{tabular}

\title{
Preliminary study report on prevalence of attention deficit hyperactivity disorder among primary school children, in selected community of Dehradun, Uttarakhand
}

\author{
Anjana Williams \\ PhD Scholar, \\ Himalayan University, Itanagar, \\ Arunachal Pradesh, India
}

\author{
Dr. Balwinder Kaur Buttar \\ NRI College of Nursing, \\ Amritsar, Punjab, India
}

\author{
Dr. Rajesh Konnur \\ Associate Professor, Kurji Holy \\ Family Hospital College of \\ Nursing, Patna, Bihar, India
}

\section{ABSTRACT}

A quantitative, cross sectional survey design was used to conduct a pilot study on 40 parents of children attending Primary school. Snowball sampling technique was used to collect the data. The objective was to see the feasibility of study on larger group and to identify the prevalence of Attention"Deficit Hyperactivity Disorder (ADHD) among primary school children. The tools used to collect data were demographic profile and Vanderbilt parents Rating Scale. The age percentage of $60 \%$ of the children was between the ages of $10-12$ years of age. Gender ratio was almost equally divided into half. The prevalence of ADHD and its subtypes showed that predominantly hyperactive/ impulsive type had more prevalent symptoms, without scoring four and five in performance. Inattentive type was found without performance disturbance among $10 \%$ of primary school children.

\section{INTRODUCTION}

Attention-deficit hyperactivity disorder (ADHD) is one of the most frequent neuro developmental disorders of childhood. Studies that followed children with ADHD to adolescence revealed that approximately $70 \%$ to $85 \%$ of the school going children has the disorder during adolescence. ADHD also continues to cause significant social and academic problems in adolescents and is usually comorbid with other psychiatric disorders. However, despite these significant findings, ADHD literature mostly relies on childhood cases. ${ }^{\mathbf{i}}$ Epidemiologic information on ADHD is scarce because of few population-based studies changing diagnostic criteria overtime.

The major limitations in the identification of ADHD was that it was on samples which are clinically referred cases, thus have small sample size. There is only a limited source of information regarding the prevalence of ADHD in the Indian context. ${ }^{\text {ii }}$ Several studies estimated a prevalence of ADHD of $4-8 \% \mathrm{in}$ USA(8), $7.6 \%$ to $9.5 \%$ in $\operatorname{Korea}(9), 10-20 \%$ in India(10), and 29.7\% in United Arab Emirates.(11) Data about prevalence of ADHD in Saudi Arabia were scarce. iii

According to DSM-IV ${ }^{\mathrm{TR}}$ criteria there are 3 major different subtypes of ADHD which includes predominantly inattentive subtype, predominantly hyperactive-impulsivesubtype, and combined inattentive/hyperactive-impulsive $1,2,3$. ADHD is one of the most prevalent chronic health disorders affecting school age children. It is also the most frequently occurring Neuro-psychiatric disorder in children. ${ }^{2,4}$

Gender wise global ADHD prevalence for males aged $5-19$ is $2.2 \%$ and for females $0.7 \%$. ${ }^{\text {iv }}$ Where 5.1 million Children $(8.8 \%$ or 1 in 11 of this age group $4-$ 17 years) have a current diagnosis of ADHD; Boys 
$(12.1 \%)$ continue to be more than twice as likely as girls (5.5\%) to have ADHD. According to the parent reports, 6.4 million children (11\% of this age group 417 years) have ever been diagnosed with ADHD, and rates of ever-diagnosed ADHD increased an average of approximately 5\% per year from 2003 to $2011 .^{v}$

Psychiatric epidemiological studies conducted in developed countries indicated that around $25 \%$ of children and adolescents meet lifetime criteria for mental disorders which includes ADHD. vi,vii and about $10 \%$ have distress or impairment that is severe and needs medical attention. ${ }^{\text {viii }}$ Attention deficit hyperactivity disorder is one of the most common childhood brain disorders and can continue through adolescence and adulthood. Symptoms include difficulty staying focused and paying attention, difficulty controlling behavior, and hyperactivity (over-activity)

These symptoms can make it difficult for a child with ADHD to succeed in school, get along with other children or adults, or finish tasks at home. Parents and teachers can miss the fact that children with symptoms of inattention have ADHD because they are often quiet and less likely to act out. They may sit quietly, seeming to work, but they are often not paying attention to what they are doing. ${ }^{\mathrm{ix}}$ The worldwide-pooled prevalence of ADHD for persons age 18 and under was $5.29^{\mathbf{x}}$

Children with ADHD often have been noted by their parents and teachers during academic and at home. In addition parents often feel disgusted to manage such children and more often the child is considered to be disobedient. The inattentiveness of child distances him from his siblings and class mates. The problems faced by these children are difficult but not insurmountable. In order to achieve his or her full potential he or she should receive help, guidance and understanding from parents and teachers as well. ${ }^{\mathbf{x}}$

There is only a limited source of information regarding the prevalence of ADHD in the Indian context. The delay in diagnosis and treatment can only lead to further complications. Parents and teachers play a pivot role in assessment of slight change in behavior. It is possible to manage ADHD and improve child's academic and social experiences, if parents will have the knowledge about the disorder and how to intervene during the times of hyperactive crisis. The current study aims at selecting parents of primary school children from a community. This study indicates the importance of early identification and thus helping in early intervention. Early diagnosis and early treatment can make a difference.

\section{METHODOLOGY}

Quantitative approach, cross sectional survey design was used to conduct study on 40 parents of children attending Primary school. The simple random sampling technique was used to select the area in Dehradun block. Parents of children attending primary school were interviewed. Written consents were taken from the participants after explaining the purpose of the study. The aim of the study was to explore the prevalence of attention deficit hyperactivity disorder and its subtypes among primary school children. The tools used were demographic profile of study subjects and Vanderbilt parents Rating Scale. The tools were translated into Hindi and retranslated into English. The validity and reliability was assessed through test and retest method and reliability was found to be $r=.9$ 


\section{STUDY RESULTS}

The study results were organized into following categories-

- Demographic variables of study participants $\mathrm{N}=\mathbf{4 0}$

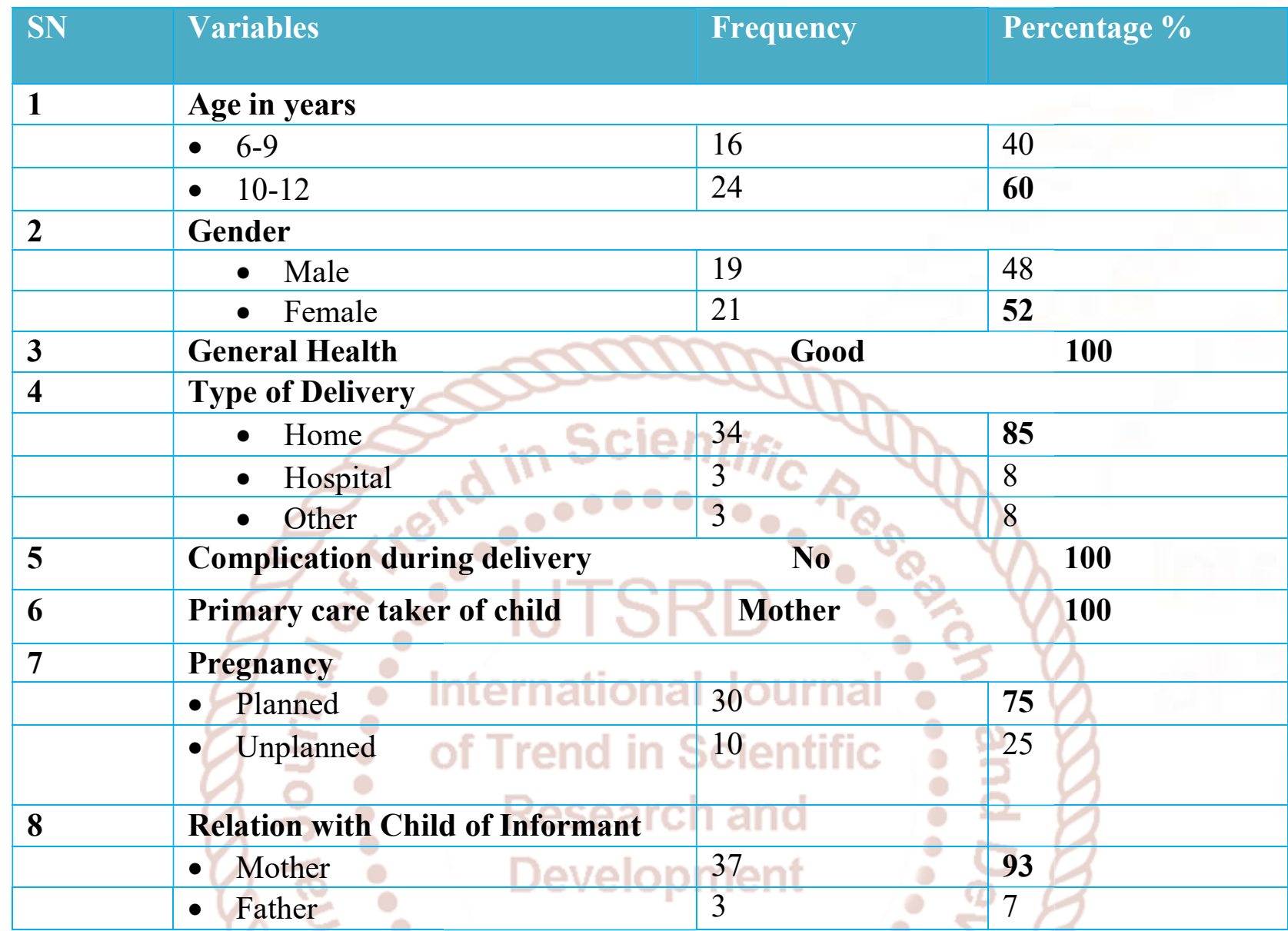

Table number 1 shows the demographic variables of the study variables. The age percentage shows that $60 \%$ of the children were between the ages of $10-12$ years of age. Gender ratio was almost equally divided into half. General health of all children was good. Type of delivery for majority $80 \%$ of the children were at home. Although majority of the deliveries were at home, still no complications were seen before and after delivery. One third pregnancies were planned and the primary care takers were all mothers.

- Prevalence of ADHD and its subtypes among Primary school children

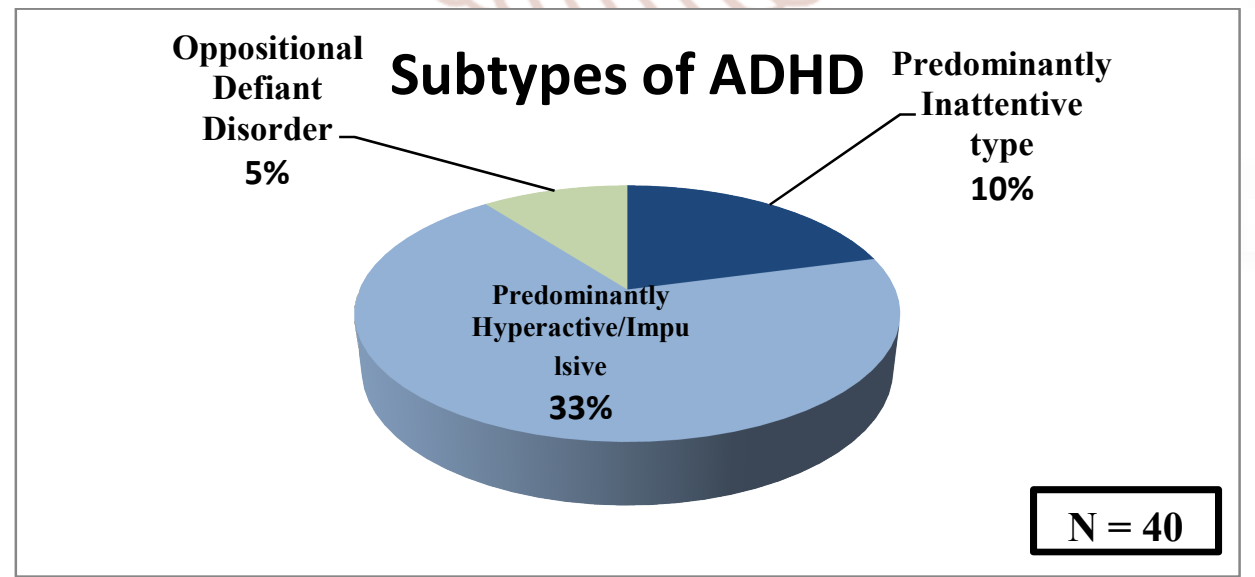

Note - any of the above subtypes are considered disorder if 2 or 3 on 6 out of 9 items and Score a 4 or 5 on any of the Performance questions 
The prevalence of ADHD and its subtypes during the pilot study on 40 primary school going children showed that predominantly hyperactive/ impulsive type signs 33\% were more prevalent, but did not have performance deficient in the score of four and five. Inattentive type was found without performance disturbance among $10 \%$ children. Two subjects scored four and five in performance questions with predominantly inattentive type. The other subtypes of ADHD was also assessed according to DSM-IV TR, i.e. ADHD Combined type, Conduct disorder, Anxiety / Depression, as it was part of Vanderbilt scale.

\section{CONCLUSION/RECOMMENDATION/}

The study results concluded that ADHD symptoms were present among primary school children but did not meet the criteria for any of the subtypes. Using snowball sampling was found to be difficult to collect the data. The recent study can be used as base for larger study to determine the prevalence of ADHD among primary school going children.

i. BedriyeOncu et al, Symptoms Defined by Parents' and Teachers' Ratings in Attention-Deficit Hyperactivity Disorder: Changes with age. The Canadian Journal of Psychiatry-Brief Communication, Can J Psychiatry, Vol 49, No 5, June 2004

ii. Prevalence of Attention Deficit Hyperactivity Disorder in primary school children

JyothsnaAkamVenkata, Anuja S. PanickerDepartment of Psychiatry, P. S. G. Institute of Medical Sciences and Research, Coimbatore, Tamil Nadu, India URL available from http://www.indianjpsychiatry.org on Saturday, April 04, 2015, IP: 14.139.239.37]

iii. Jamal H. Al Hamed et al, Attention Deficit Hyperactivity Disorder (ADHD) among Male Primary School Children in Dammam, Saudi Arabia: Prevalence and Associated Factors, J Egypt Public Health Assoc. Vol. 83 No. 3 \& 4, 2008

iv. Erskine et al. (2013 December), Research Review: Epidemiological modeling of attentiondeficit/hyperactivity, disorder and conduct disorder for the Global Burden of Disease Study 2010, Journal of Child Psychology and Psychiatry, volume 54 n12, pp. 1263-1274

v. Trends in the Parent-Report of Health Care Provider-Diagnosis and Medication Treatment for ADHD: United States, 2003-2011 data available from the National Survey of Children's Health (NSCH) 2003 to 2011

vi. Srinath S, Girimaji SC, Gururaj G, Seshadri S, Subbakrishna DK, Bhola P, et al. Epidemiological study ofchild \&and adolescent psychiatric disorders in urban and rural areas of Bangalore, India. Indian $\mathrm{J}$ Med Res 2005; 122:67-79

vii. Costello EJ, Mustillo S, Keller G, Angold A. Prevalence of psychiatric disorders in childhood andadolescence. In: Levin BL, Petrila J, Hennessy KD (Eds.). Mental Health Services: a Public
HealthPerspective. Ed 2. Oxford, UK: Oxford University Press 2004; pp111-128.

viii. Brauner CB, Stephens CB. Estimating the prevalence of early childhood serious emotional/behavioraldisorders: challenges and recommendations Public Health Rep 2006; 121:303310

ix. National Institute of Mental Health U.S. Department of Health and Human ServiceS national institutes of Health

x Polanczyk et al. (2007 June), The worldwide prevalence of ADHD: a systematic review and metaregression analysis, American Journal of Psychiatry, June 2007, v164 n6, pp. 942-948

Zwi M, Jones H, Thorgaard C, York A, Dennis JA. Parent training interventions for Attention Deficit Hyperactivity Disorder among children, Cited on Feb. 2015 Available from URL http://www.ncbi.nlm.nih.gov/pubmed/22161373

${ }^{x i}$ M.S.Jacintha.R.Mariyappa, effectiveness of behavioral therapy in children with ADHD, nightingale nursing times 2007.9(3) Page 63-64. 